\title{
ANÁLISE DE UMA POLÍTICA PÚBLICA DE LAZER A PARTIR DA IMPLEMENTAÇÃO E GESTÃ̃O DO PROGRAMA ACADEMIA A CÉU ABERTO DA CIDADE DE BELO HORIZONTE/MG
}

Recebido em: 28/12/2020

Aprovado em: 04/03/2021

Licença:@) (1) @

Natascha Stephanie Nunes Abade 1

Brisa de Assis Pereira ${ }^{2}$

Universidade Federal de Minas Gerais (UFMG)

Belo Horizonte - MG - Brasil

RESUMO: A Academia a Céu Aberto é uma política pública que tem como objetivo implantar equipamentos de ginástica adaptados e sem peso em praças e parques da cidade de Belo Horizonte/Minas Gerais (MG). O objetivo deste artigo foi investigar a implementação e gestão desse Programa com foco na estrutura normativa e organizacional. Como metodologia, foram realizadas pesquisas documentais e de campo a partir de uma entrevista semiestruturada com um técnico responsável pela sua gestão. Foi identificado que não há um projeto com as normas e diretrizes dessa política, sendo essa ação de lazer relacionada com uma prática simplista, atrelada a tudo que não é competitivo e condicionada à saúde. Além disso, a política não possui um monitoramento, o que pode interferir na sua gestão e continuidade. Por fim, estudos que relacionam a implementação de políticas públicas de lazer são recentes e contribuem para uma reflexão crítica sobre a temática.

PALAVRAS-CHAVE: Academia a Céu Aberto. Política Pública. Atividades de Lazer.

\section{ANALYSIS OF A LEISURE PUBLIC POLICY FROM THE IMPLEMENTATION AND MANAGEMENT OF THE OUTDOOR GYM PROGRAM OF THE CITY OF BELO HORIZONTE/MG}

ABSTRACT: The Outdoor Gymis a Public Policy that aims to implement adapted and weight less gymnastic equipment in squares and parks in the city of Belo Horizonte/MG. The aim of this article was to investigate the implementation and management of this Program focusing on its normative and organizational structure. As a methodology, documentary and Field research were used from a semi-structured interview with a technician responsible for the management of the Program. It was

\footnotetext{
${ }^{1}$ Doutoranda e Mestre pelo Programa de Pós-graduação Interdisciplinar em Estudos do Lazer (PPGIEL) da Universidade Federal de Minas Gerais (UFMG). Bacharel em Educação Física pela UFMG. Licenciada em Educação Física pelo Centro Universitário Claretiano. Grupo de Estudo e Pesquisa POLIS/UFMG.

${ }^{2}$ Doutoranda e Mestra pelo Programa de Pós-graduação Interdisciplinar em Estudos do Lazer (PPGIEL) da Universidade Federal de Minas Gerais (UFMG). Bolsista da Coordenação de Aperfeiçoamento de Pessoal de Nível Superior - Brasil (CAPES). Bacharel em Educação Física pela UFMG. Licenciada em Educação Física pelo Centro Universitário Claretiano. Grupo de Estudo e Pesquisa POLIS/UFMG.
} 
identified that there is no Project with the norms and guidelines of this policy, and this leisure action is related to a simplistic practice, linked to everything that is not competitive and conditioned to health. In addition, the policy does not have a monitoring, which can interfere with its management and continuity. Finally, studies that relate the implementation of leisure public policies are recent and contribute to a critical reflection on the theme.

KEYWORDS: Outdoor Gym. Public Policy. Leisure Activities.

\section{Introdução}

O presente artigo é um recorte de uma pesquisa mais ampla, desenvolvida no mestrado, que teve como objetivo principal investigar o Programa Academia a Céu Aberto da cidade de Belo Horizonte ${ }^{3}$. Tendo como norte o referido tema, busca-se aqui apresentar e discutir os dados acerca das Academias a Céu Aberto (ACA), a partir da visão de um dos gestores dessa política e das diretrizes da Secretaria Adjunta de Esporte e Lazer.

O artigo foi desenvolvido a partir do campo de estudo específico das políticas públicas, sendo caracterizado como estudo de caso combinado a um estudo exploratório-descritivo (AMARAL; GOMES, 2005). A partir deste campo de investigação e levando em consideração as fases constitutivas do processo político percepção/definição de um problema, elaboração de programas e decisão (inserção na pauta política) até sua implementação, avaliação e eventual correção (FREY, 2000) - o foco do presente artigo relacionou-se à fase de implementação das políticas de lazer, uma vez que buscou compreender o que ocorre no momento de materialização/concretização da mesma.

Inicialmente, problematizou-se os dados obtidos por meio de uma entrevista semiestruturada realizada com um representante (designado pela extinta Secretaria

\footnotetext{
${ }^{3}$ Dissertação de Mestrado intitulada "As academias a céu aberto em Belo Horizonte: interfaces entre lazer e saúde", defendida no ano de 2016. A dissertação foi desenvolvida no Programa de Pós-Graduação Interdisciplinar em Estudos do Lazer (PPGIEL) da Universidade Federal de Minas Gerais (UFMG).
} 
Adjunta de Lazer) que estava vinculado diretamente às Academias a Céu Aberto no ano de 2015. Foi realizada somente uma entrevista, uma vez que a Secretaria apresentou limitações, oriundas do fato de haver apenas um técnico responsável pela implementação da política dentro do setor.

Ao realizar a entrevista semiestruturada, "embora sejam feitas perguntas específicas, o entrevistado possui um espaço para falar livremente, e o pesquisador pode elaborar questões não previstas inicialmente, mas que podem ser importantes para a compreensão de seu problema de pesquisa" (AMARAL; GOMES, 2005, p. 75). Sendo assim, o roteiro da entrevista foi elaborado no sentido de entender como se dá a gestão das Academias a Céu Aberto e não ocorreu de forma estática, havendo interação com o entrevistado.

Após apresentado o Termo de Anuência e o Termo de Consentimento Livre e Esclarecido, a entrevista foi realizada indo a campo na Secretaria Adjunta de Lazer. A identidade do pesquisado foi mantida em sigilo e a entrevista foi analisada juntamente com os documentos acessados sobre o projeto das Academias a Céu Aberto, que serão apresentados no capítulo seguinte em diálogo com o referencial teórico.

Uma vez que o foco de investigação do presente artigo é a implementação dessa política de lazer, utilizou-se das proposições de Linhales et al. (2008), como opção metodológica para auxiliar na interpretação da entrevista. Sendo assim, considerou-se o ordenamento institucional do setor, as condições de estrutura física para a gestão e para o desenvolvimento do programa, o quadro pessoal envolvido nos diferentes níveis de planejamento e execução, a disponibilidade de recursos financeiros e como ela se apresenta no orçamento, e por fim, as estratégias construídas ou não para o envolvimento da população no processo de gestão e controle social. 
Para a interpretação dos dados, foi utilizada a análise de conteúdo que consiste em empreender um estudo minucioso de seu conteúdo, das palavras e frases que compõem as respostas obtidas. As unidades de contexto estão referenciadas ao longo de todo o texto e servem "de unidade de compreensão para codificar a unidade de registro e correspondem ao segmento da mensagem" (BARDIN, 2012, p.137). Segundo Bardin (2012), esse procedimento se refere às unidades de registro, sendo "o segmento do conteúdo considerado unidade de base, visando a categorização" (p. 134).

Por fim, buscando descrever a estrutura normativa-organizacional que compõe as Academias a Céu Aberto, delimitou-se como fonte as informações acessadas pelo site da Prefeitura de Belo Horizonte e cedidas pela Secretaria Municipal Adjunta de Esporte e Lazer. A análise dessas fontes possibilitou compreender como esse Programa foi implantado e vem sendo executado atualmente, servindo como base no entendimento da política das Academias a Céu Aberto.

$\mathrm{O}$ artigo está dividido em duas partes. A primeira destinada a apresentar o aparato teórico que orienta a compreensão do objeto de estudo, articulando as políticas públicas, o processo de implementação de uma política e as políticas de lazer em Belo Horizonte. E, a segunda parte, destinada a analisar a implementação das Academias a Céu Aberto a partir da fala do gestor responsável por seu desenvolvimento, dialogando com os dados documentais atualizados desse Programa de lazer e com pesquisas recentes sobre a temática. Nessa seção o objetivo é problematizar tanto as questões gerenciais (ordenamento institucional, quadro de pessoal, normas e diretrizes do programa, demanda populacional, financiamento, etc.), quanto as concepções de lazer adotadas na implementação dessa política. 


\section{Política e Implementação de Políticas Públicas}

Diversos conceitos e definições são utilizados para problematizar a política e a política pública. Pensar no termo política nos remete ao seu contex to histórico de estudo que se iniciou em 1950 nos Estados Unidos com a denominação de policy science (FREY, 2000). Na Europa esses estudos iniciaram a partir da década de 70 e, no Brasil, tal tema é relativamente recente uma vez que foi a partir da constituição da democracia, em 1988, que o país iniciou o seu caminho no que diz respeito às políticas de garantia de direitos, principalmente ao se pensar as políticas públicas de lazer.

Chauí (2000) define que o surgimento da política está relacionado ao surgimento das cidades:

\footnotetext{
Para responder às diferentes formas assumidas pelas lutas de classe, a política é inventada de modo que, a cada solução encontrada, um novo conflito ou uma nova luta podem surgir, exigindo novas soluções. Ao invés de reprimir os conflitos pelo uso da força e das armas, a política surge como legitimação dos conflitos, de tal forma que o fracasso nesse trabalho é a causa do uso da força e da violência, de alguma forma apontando um defeito do comportamento político do sistema (CHAUí, 2000, p. 485).
}

Seguindo a mesma direção, Rua (1997) considera que a política surge como um "conjunto de procedimentos formais e informais que expressam relações de poder e que se destinam à resolução pacífica dos conflitos quanto a bens públicos” (RUA, 1997, p. 1). A política está presente na vida dos sujeitos cotidianamente e se relaciona com a necessidade de convivência de diversos interesses que demandam atendimento e competem entre si. Pensando dessa maneira, percebe-se que em certos contextos determinados atores terão destaque e maior investimento em relação ao processo de formulação e implementação de uma política.

A autora enfatiza ainda a dimensão pública das políticas, ao afirmar que esta

[...] é dada não pelo tamanho do agregado social sobre o qual incidem, mas pelo seu caráter "imperativo". Isto significa que uma das suas características centrais é o fato de que são decisões e ações revestidas da autoridade soberana do poder público. As políticas públicas envolvem, portanto, atividade política (RUA, 1997, p. 2). 
Uma política pública pode se organizar de diferentes maneiras, sendo caracterizada como programas, projetos ou ações, que têm em comum algumas de suas características como, o conteúdo, a normativa, os objetivos, o alcance, entre outros fatores (MENICUCCI, 2006).

A partir de todo o exposto, a definição de política pública não perpassa somente pela demanda da sociedade sobre determinado programa - projeto, ação -, e sim, por conflitos políticos como, alocação de recursos, locais de instalação, prioridade de execução, dentre outros, para se tornar uma política pública em si. Considerar o governo atuante no momento, os seus aliados, as suas prioridades e sua linha de atuação, são fatores importantes ao analisar uma política pública, pois, como ressaltado pelos autores, ela é o resultado dessa atividade política.

Em síntese, Souza propôs que a política pública é um campo do conhecimento que busca "colocar o governo em ação e/ou analisar essa ação (variável independente) e, quando necessário, propor mudanças no rumo ou curso dessas ações (variável dependente)" (SOUZA, 2006, p. 27). Assim, as políticas públicas se destinam a modificar características de algum cenário social que são consideradas importantes pelas autoridades.

Frey (2000) aponta três dimensões da política pública que auxiliam na compreensão da temática. A primeira é a esfera política (polity), que se refere "à ordem do sistema político, delineada pelo sistema jurídico, e à estrutura institucional do sistema político-administrativo" (p. 216), ou seja, a organização do sistema político em si e sua parte conceitual. A segunda é a atividade política (politics), que tem como ponto central "o processo político, frequentemente de caráter conflituoso, no que diz respeito à imposição de objetivos, aos conteúdos e às decisões de distribuição" (p. 216), ou seja, a política partidária, de disputa e de mobilização. E, a terceira, é a ação pública 
(policy/policies), sendo “os conteúdos concretos, isto é, à configuração dos programas políticos, aos problemas técnicos e ao conteúdo material das decisões políticas” (p. 217), em outras palavras, o processo de elaboração e implementação da ação pública.

De acordo com Amaral (2014), “esses termos são utilizados em inglês, pois a palavra política em português é polissêmica, incorporando numa só palavra as três dimensões e adjetivar a política com o vocábulo pública significa afirmar que se trata da ação do Estado, revestido de autoridade" (p. 140), a fim de assegurar os diferentes direitos existentes. Ao considerar que essa abordagem faz uma divisão de categorias de análises, é importante salientar que na realidade política essas dimensões são entrelaçadas e se influenciam constantemente.

Lasswell (1956) apresenta uma proposta teórico-metodológica intitulada "Modelo Sequencial”, ou Ciclo Político (policy cycle), que busca realizar uma análise estruturada do processo político por meio da sua decomposição em fases sucessivas (e relacionadas entre si) de uma forma lógica e sequencial. Desta forma, ao formular o conjunto de etapas do processo político o autor propôs uma classificação em sete fases, entretanto, a literatura adotou como usual a análise baseada em cinco fases sucessivas, interligadas e dinâmicas: 1) definição do problema; 2) conformação da agenda; 3) formulação, elaboração de programas e decisão; 4) implementação; e, 5) avaliação e eventual correção (MENY; THOENIG, 1992; FREY, 2000; ROTH, 2002; STAREPRAVO; SOUZA; JUNIOR, 2011).

Embora adote tal classificação, Frey (2000) destaca as diferenciações nas divisões do ciclo político e compreende como comum a todos os modelos as fases de formulação, de implementação e de controle dos impactos da política. De tal forma, dentro do modelo detalhado anteriormente, unifica as fases 1) "definição do problema" e 2) "conformação da agenda" em uma única: 1) percepção e definição de problemas 
(agenda-setting), 2) elaboração de programas e decisão, 3) implementação de políticas e, finalmente, 4) avaliação de políticas e eventual correção da ação. Segundo o autor, esse ciclo é direcionado por um processo de constantes mudanças e de diferentes maneiras de usos dos estágios, devido ao jogo político que engloba a disputa de interesses dos atores envolvidos.

A percepção e definição de problemas é uma fase que corresponde à escolha de um determinado campo de ação dentre os diversos apresentados para um tratamento político, ou seja, como é feita a escolha do problema dentro dos processos políticos. Windhoff-Héritier (1987) salienta que "problemas do ponto de vista analítico só se transformam em problemas de policy a partir do momento em que adquirem relevância de ação do ponto de vista político e administrativo" (p. 68). A fase de elaboração de programas e decisão é considerada a forma de ação escolhida dentre as diversas possibilidades disponíveis. A implementação é a fase “cuja encomenda de ação é estipulada na fase precedente à formulação das políticas e a que, por sua vez, produz do mesmo modo determinados resultados e impactos de policy" (WINDHOFF-HÉRITIER, 1987, p. 228). Muitas vezes, nessa fase os resultados e impactos reais não correspondem aos projetados, enfatizando, com isso, a importância de uma análise no conteúdo da elaboração em comparação com o executado. Já na fase da avaliação de políticas e da correção de ação leva-se em consideração os programas implementados e seus possíveis impactos muitas vezes direcionados pela efetividade, eficácia e eficiência.

Do ponto de vista metodológico, o policy cycle reduz a complexidade da formulação das políticas públicas ao dividi-la em um conjunto pequeno de etapas e subetapas, que podem ser analisadas de maneira independente ou estabelecendo relação com algumas ou todas as etapas do ciclo. Neste sentido, Starepravo; Souza e Junior (2011) alertam para o caráter didático e analítico do modelo que deve ser utilizado a 
partir da noção clara de que é apenas uma representação simplificada da realidade, um facilitador analítico do processo político, "uma vez que na política real ou efetiva, muitas vezes os passos se sobrepõem ou se confundem" (p.247).

A partir da explicação da composição do policy cycle, é possível perceber que esse modelo se baseia numa abordagem sequencial. Pode ser considerado um modelo linear, onde as estruturas não se intercedem, o que não o desconsidera como uma importante ferramenta inicial de análise de políticas públicas. Por isso, a literatura atual tem se esforçado em discutir esse modelo a partir de um ciclo de política circular, no qual todas as fases se entrelaçam.

O presente artigo elege como ponto central de sua análise a etapa da implementação, uma vez que, segundo Pollitt (2013 apud Lotta, 2019), "é por meio da implementação de serviços públicos que os governos constroem e fundamentam sua legitimidade, já que eles são a face mais visível do estado” (p. 34), em outras palavras, nessa fase o que foi formulado é colocado em prática. Lotta (2019) afirma que este é o momento que depende fortemente da ação dos atores envolvidos na política e dos instrumentos de ação que serão adotados.

Em conformidade a isso, Arretche (2004) afirma que geralmente há uma grande distância entre os objetivos e o desenho concebidos originalmente pelos formuladores das políticas públicas e a tradução de tais concepções em intervenções públicas. Essa distância diz respeito as contingências da implementação, explicadas, em grande parte, pelas decisões tomadas por uma cadeia de implementadores no contexto político, social, institucional e econômico em que operam.

Conforme afirma Lotta (2019),

Analisar como esses serviços e políticas públicas são concretamente construídos por meio da ação prática de burocratas que transforma ideias abstratas em ações concretas é o grande objetivo desse campo que, dessa forma, tem muito a contribuir tanto teórica quanto empiricamente (LOTTA, 2019, p.34). 
Buscar exercer esse olhar sobre o que os atores envolvidos de fato concretizam ao implementar uma política pública é um caminho para as pesquisas que têm como enfoque a análise da implementação. Lima e D’Ascenzi (2013) apontam duas abordagens hegemônicas na literatura sobre implementação de políticas públicas:

Uma delas toma como foco de análise o processo de formulação da política pública, e as variáveis destacadas são referentes às normas que a estruturam. A segunda abordagem enfatiza elementos dos contextos de ação nos quais a política será implementada. Toma como variáveis as condições dos espaços locais e as burocracias implementadoras (LIMA; D’ASCENZI, 2013, p. 102).

Segundo os autores Muller e Surel (2002), a primeira perspectiva baseia-se na abordagem sequencial, ou seja, a política pública é vista como uma sequência de etapas distintas e guiadas por lógicas diferentes. Essa perspectiva é denominada top-down ou desenho prospectivo (ELMORE, 1996). Seu principal foco é entender como os objetivos previamente propostos (democraticamente) foram modificados pelos atores envolvidos na implementação (LOTTA, 2019).

O segundo modelo analítico questiona uma análise com uma visão ascendente, no qual há uma influência da discricionariedade dos atores ao implementar a política, uma vez que esses detêm conhecimento das situações locais e podem adaptar o plano a elas (O'BRIEN; LI, 1999). Essa abordagem é comumente denominada bottom-up ou desenho retrospectivo (ELMORE, 1996). Segundo Lotta (2019), esse modelo considera que as políticas públicas são compostas por várias atividades políticas e que "a implementação é apenas uma parte desse processo e ela também exige decisões, isso porque nem tudo é passível de ser previsto, controlado ou normatizado" (p.16).

A junção dessas duas tendências gerou os modelos híbridos de análise na tentativa de articular as relações entre diferentes níveis de governo, além de indicar a restrição de explicações lineares do processo de implementação. Isso se dá porque "a interpretação da estrutura normativa de uma política pública é influenciada pelas 
concepções de mundo dos atores que irão executá-la e de suas condições materiais" (LIMA; D’ASCENZI, 2013, p. 104).

Visto isso, torna-se necessário entender o contexto dos estudos das políticas públicas para assim buscar compreender um objeto específico de análise que, no caso deste artigo, será uma política pública de lazer em destaque na cidade de Belo Horizonte.

\section{Políticas Públicas de Lazer e a Cidade de Belo Horizonte}

O processo de redemocratização que ocorreu no Brasil na década de 1980, originando a formulação da Constituição Federal (CF/88), abriu caminhos para o debate acerca da garantia de direitos à população. Conhecida como Constituição Cidadã, a CF/88 abrangeu em seu escopo a defesa por uma série de direitos sociais que serviram futuramente de base para a estruturação de políticas públicas setoriais nas mais diversas áreas, dentre estas o lazer, artigo $6^{\circ}$ da Constituição. O status de direito constitucional galgado pelo lazer colocou em evidência a obrigação do Estado em garantir sua concretização por meio da democratização do acesso e inclusão social às vivências de lazer (MENICUCCI, 2008).

Entretanto, diferentemente dos direitos civis e políticos que compõem a noção moderna de cidadania (MARSHALL, 1967), a condução dos direitos sociais no Brasil é marcada pela carência de documentos normativos estratégicos (MENICUCCI, 2006). Assim, segundo Silva, et al. (2013), as políticas de lazer ficam dispersas, fragmentadas em textos infraconstitucionais muitas vezes pouco articulados. Como exemplo pode-se citar o Estatuto da Criança e do Adolescente (1990), o Estatuto do Idoso (2003), a Lei Brasileira de Inclusão (2016) e a Declaração dos Direitos Humanos (1948). 
Para além desses, vale a menção ao artigo 220 da Constituição Estadual de Minas Gerais (1989), Seção VII - Do Desporto e do Lazer, que indica que compete ao Poder Público apoiar e incentivar o lazer, reconhecendo-o como forma de promoção social. Por fim, ao Estatuto da Cidade (Lei 10.257 de 2001), onde o lazer é enfatizado como direito a ser garantido no planejamento da cidade, por meio de políticas urbanas municipais que garantam seu acesso à toda a população.

Menicucci (2008), ao considerar que a definição do direito social ao lazer não foi acompanhada pelo arcabouço legal que garanta sua concretização, assinala que as práticas de lazer são desenvolvidas a partir de iniciativas autônomas e isoladas. Nas palavras da autora, "na ausência de uma política nacional explícita ou articulada, as políticas locais de lazer seguem diretrizes próprias e, na maioria das vezes, há uma percepção de que isso se faz de forma ainda frágil no contexto dos governos locais" (p.180).

No caso da cidade de Belo Horizonte e do Estado de Minas Gerais, Pinto (2013), por meio de um levantamento histórico, indica que essas políticas foram pautadas por um conjunto de ações que buscavam a educação de corpos a partir do objetivo político e social de cada momento do governo. Segundo a autora, estes pautaram suas ações, ao longo dos anos, por quatro diretrizes principais: a primeira, voltada à educação corporal, compreendeu do controle do corpo à descoberta de talentos; a segunda, voltada à valorização da construção de obras de infraestrutura esportiva por todo o estado, tornouse uma das marcas do governo de Minas; a terceira, assumindo a política de eventos, reafirmou a valorização da cultura dos eventos discriminatórios, a distribuição de materiais esportivos e realizações de "ruas de recreio" esporádicas; e, a quarta, revelando o uso político do lazer, vinculou a educação escolar à políticas 
compensatórias, assistencialistas, utilitaristas e, ainda, como instrumento políticoeleitoral.

De acordo com Munhoz (2008) a Prefeitura de Belo Horizonte (PBH) passou, a partir dos anos 2000, por uma reforma político-administrativa que alterou seu desenho organizacional e gerencial, objetivando modernizar e melhorar os serviços prestados à população.

Através de um estudo que objetivou mapear as ações relacionadas à promoção do lazer que foram realizadas, direta ou indiretamente, pela Prefeitura de Belo Horizonte em 2005, Munhoz (2008) constatou que (na época) o que se verificava na PBH não era exatamente a existência de uma política pública unificada de lazer, mas sim estratégias governamentais para o tratamento de problemas como pobreza, exclusão social e desigualdade de acesso a bens e serviços, dentre eles o lazer.

Segundo a autora, embora existisse uma atuação do governo municipal para efetivar o direito ao lazer, as ações não estavam organizadas em uma única política articulada e bem delimitada. Ou seja, não existia um programa dedicado deliberadamente à promoção do lazer, com orientações normativas claras. As ações voltadas à sua garantia estavam dispersas entre a Secretaria Municipal Adjunta de Esportes (que se relacionava de forma mais acentuada com os interesses físicos), com a Fundação de Parque Municipais, com a Fundação Municipal de Cultura e com a Empresa Municipal de Turismo de Belo Horizonte.

Segundo Bichir (2011), a estrutura burocrática é uma dimensão extremamente relevante para compreender a capacidade estatal de implementação das políticas públicas. Nessa perspectiva Oliveira (2020), ao analisar a implementação das políticas públicas de esportes e lazer para pessoas com deficiência no município de Belo Horizonte/MG, se debruçou sobre a estrutura burocrática do governo municipal e 
recorreu a um grande volume de documentos que ajudaram a traçar uma linha temporal mais recente acerca do arcabouço normativo que rege a política de esporte e lazer na cidade de Belo Horizonte.

Ao encontro com o estudo de Munhoz (2008), a autora indica que entre os anos 2000 e 2011, o esporte foi incorporado à Secretaria Municipal de Esportes. Entretanto, acrescenta que apenas em 2011 a temática ganhou status de pasta única, a partir da criação da Secretaria Municipal de Esportes e Lazer. Esta, por sua vez, se tornou responsável pelo planejamento, direção, execução, controle e avaliação dos programas, projetos e ações de esportes e lazer do município voltados para crianças, jovens, adultos, idosos e pessoas com deficiência (OLIVEIRA, 2020, p. 62).

No âmbito do financiamento das políticas públicas - aqui compreendido como um mecanismo fundamental para dar materialidade a uma política -, destaca-se a pesquisa de Silva et al. (2019) sobre o orçamento municipal de Belo Horizonte para as políticas de esporte e lazer, entre os anos de 2014 e 2017. Segundo os autores, é possível perceber a existência de uma concepção ampliada acerca desses fenômenos nos documentos que integram as etapas de planejamento e orçamento do município (o esporte e o lazer são compreendidos como direitos constitucionais; como bens culturais historicamente construídos; como instrumentos de melhoria da qualidade de vida das pessoas; como favoráveis à socialização humana; como direitos do cidadão e dever do Estado; dentre outros). E, ainda, que o fato de a cidade possuir uma Secretaria Municipal de Esporte e Lazer (SMEL) configura um passo primordial para a garantia desses direitos.

Entretanto, a pesquisa ressalta que, apesar do discurso ampliado e da existência de uma Secretaria própria, ao analisar as ações implementadas e a verba destinada anualmente ao esporte e ao lazer, percebe-se que apenas $0,73 \%$ dos recursos (menos que 
$1 \%$ do Orçamento Municipal Anual) é alocado nessas políticas; que existe um enfoque à projetos esportivos (educacionais e de rendimento) em detrimento das demais práticas e vivências de lazer; e, ainda, que as ações são voltadas à manutenção, qualificação e implementação de equipamentos e estruturas, não contemplando a riqueza de significados conferidos ao esporte a ao lazer pelos próprios documentos.

Como os estudos de Silva et al. (2019) e Oliveira (2020) revelam, as políticas de esporte e lazer passaram a ser desenvolvidas, na cidade de Belo Horizonte, por meio da Secretaria Municipal de Esportes e Lazer (SMEL), que abarcava a Secretaria Municipal Adjunta de Esportes (SMAE) e a Secretaria Municipal Adjunta de Lazer (SMAL). Essa estrutura se manteve até o ano de 2017 e, atualmente, essas Secretarias Adjuntas foram fundidas tornando-se uma única Secretaria Municipal Adjunta de Esporte e Lazer.

Segundo o sítio eletrônico oficial, a SMEL se dedica à elaboração, execução, monitoramento e avaliação de políticas públicas da área com base no preceito da inclusão social. Por meio de seus programas, atende mensalmente (direta e indiretamente) cerca de 30 mil crianças e adolescentes, jovens e adultos, idosos e pessoas com deficiência em núcleos próprios, escolas, pistas de caminhada e praças, instituições de longa permanência e em ações de lazer, dentre outros.

Para executar suas ações, o Governo Municipal possui equipamentos específicos distribuídos na cidade, contando, com 768 equipamentos públicos disponíveis para a população: 155 quadras (poliesportivas, futebol society, tênis e peteca); 08 ginásios poliesportivos, com iluminação interna, arquibancada, vestiários, banheiros, entre outras edificações (regional Barreiro, Nordeste, Noroeste e Norte); 109 campos de futebol (60 possuem medidas oficiais, 18 tem dimensões maiores que society e menores que oficiais); e 21 pistas de skate . $^{4}$

\footnotetext{
${ }^{4}$ Disponível em: https://prefeitura.pbh.gov.br/esportes-e-lazer/infraestrutura-esportiva. Acesso em: 22 nov. 2020.
} 
Belo Horizonte possui ainda mais de 75 parques (cerca de 40 possuem nascentes, córregos ou lagoas), 01 Jardim Zoológico (que abriga um borboletário, um aquário temático da bacia hidrográfica do Rio São Francisco, um jardim japonês e um jardim botânico), além de contar com mais de 790 praças públicas distribuídas pelas regionais da cidade. Estes espaços verdes, apesar de configurarem lócus que abrigam as vivências de lazer, não são de responsabilidade da SMEL e sim da Fundação de Parques e Zoobotânica 5 .

Entre as ações instituídas atualmente na SMEL, há os seguintes programas e projetos: Jogos Escolares de Belo Horizonte, BH é da Gente, Vida Ativa, Seleções do Futuro, Copa dos Campeões de Futebol Amador, Superar, Esporte para Todos, Esporte Esperança, Caminhar, No domingo a rua é nossa, Copa Centenário e Academia a Céu Aberto, esta última, objeto de investigação do presente artigo.

A Academia a Céu Aberto (ACA) em Belo Horizonte foi criada pela Prefeitura (PBH) em 2010, através da Secretaria Municipal de Esporte e Lazer (SMEL), visando à instalação de equipamentos de ginástica em praças e espaços públicos da cidade. Atualmente o Programa é administrado pela SMEL por meio da Diretoria de Infraestrutura Esportiva e conta com mais de 400 academias instaladas nas nove regionais da cidade.

Cada Academia possui de 6 a 12 equipamentos e alguns aparelhos se adaptam ao usuário utilizando o peso do próprio corpo. A utilização dos equipamentos é indicada para maiores de 12 anos. Segundo o site da PBH, o Programa Academias a Céu Aberto além de aumentar os locais de convivência, cria uma rotina de prática de exercícios ao ar livre e estes espaços contribuem para a melhoria da saúde e condicionamento físico da comunidade.

\footnotetext{
5 Disponível em: http://prefeitura.pbh.gov.br/fundacao-de-parques-e-zoobotanica. Acesso em: 22 nov. 2020.
} 
Dada a importância e abrangência do Programa, diversos estudos problematizaram as Academias a Céu Aberto no seu foco de investigação em diferentes locais do Brasil. Foram levantados, por meio do Google Acadêmico e do Portal CAPES, 21 trabalhos que relacionavam com essa discussão, sendo: duas dissertações em Ciências Humanas; quatro monografias de conclusão de curso em Educação Física; dois capítulos de livro; 14 artigos em revistas eletrônicas relacionadas à área da Educação Física, Esporte, Fisiologia, Cultura, Administração e Gestão Pública; além de 12 resumos publicados em anais de Congressos relacionados à Educação Física, Esporte, Saúde e Gestão. Essa pesquisa foi realizada em bases acadêmicas e auxiliou na compreensão e desenvolvimento do objeto de pesquisa. A partir desse estado da arte sobre as Academias a Céu Aberto, percebe-se que a maioria dos trabalhos buscaram entender esse Programa sob o prisma da Fisiologia e da Psicologia.

Especificamente em Belo Horizonte não havia nenhuma pesquisa acadêmica que buscava analisar as Academias a Céu Aberto no ano de 2014, período em que se iniciou o trabalho de dissertação que deu origem ao atual artigo, e atualmente as publicações encontradas são desdobramentos dessa pesquisa de mestrado.

Sendo assim, com o objetivo principal de investigar o Programa Academia a Céu Aberto desenvolvido na cidade de Belo Horizonte, busca-se aqui destacar aspectos referentes à fase de implementação dessa política a partir da visão de um dos gestores responsáveis por seu desenvolvimento. Além de apresentar os dados documentais atualizados sobre as Academias a Céu Aberto em diálogo com pesquisas recentes sobre a temática, problematizando os investimentos e continuidade dessa política. 


\section{Implementação das Academias a Céu Aberto}

As Academias a Céu Aberto são inspiradas em modelos da China, onde o governo criou, em 1998, as academias de ginástica ao ar livre. A ideia era estimular a prática de atividade física na população, visando à realização das Olimpíadas em Pequim de $2008^{6}$. No Brasil, desde 2005, o Ministério da Saúde vem desenvolvendo estratégias de financiamento para que as cidades voltem suas ações para a promoção da saúde, sendo que a ênfase dos projetos tem sido na atividade física.

A partir do lançamento do Programa Brasil Saudável, cumprindo com o compromisso das diretrizes e ações previstas na estratégia global de alimentação e atividade física, proposta pela Organização Mundial de Saúde (OMS, 2002), houve um investimento nos espaços de prática de atividade física no país, surgindo, então, as Academias ao Ar Livre.

Enfatizando esse investimento, o Ministério da Saúde criou, no ano de 2011, o Programa Academia da Saúde no âmbito do Sistema Único de Saúde (SUS), documento este disponibilizado no site do Ministério, para ser implantado pelas Secretarias de Saúde dos Municípios. O objetivo principal desse Programa é contribuir na promoção da saúde da população, partindo da implantação de polos com infraestrutura, equipamentos e quadro de pessoal qualificado para a orientação de práticas corporais, modos de vida saudáveis, atividade física e práticas de lazer. Dessa maneira, a partir da instalação de polos fixos, na parte que é denominada como área dos equipamentos, surge a Academia da Saúde.

Vale ressaltar as diferentes denominações que esse Programa recebe no país, como: Academia a Céu Aberto, Academias ao ar Livre, Academias da Terceira Idade,

\footnotetext{
6 Disponível em: http://revistaepoca.globo.com/Revista/Epoca/0,,EMI211860-15230,00-
} ACADEMIA+AO+\%20AR+LIVRE+VALE+A+PENA.html 
Análise de uma Política Pública de Lazer a partir da Implementação e Gestão...

Natascha Stephanie Nunes Abade e Brisa de Assis Pereira

Academias da Saúde, entre outros. Essa diferença se deve ao fato de que cada município implanta a política conforme suas Secretarias e formas de financiamento.

Em Belo Horizonte, muitas vezes essa política é confundida com o Programa Academia da Cidade $^{7}$. O discurso vinculado às Academias a Céu Aberto ${ }^{8}$ consiste em proporcionar condições adequadas para a prática de atividades físicas, de lazer e esporte através do desenvolvimento de políticas públicas inclusivas, que garantam a participação de todos e promovam a qualidade de vida urbana, contribuindo para a consolidação de ambientes sociais saudáveis, educativos e seguros. Ao perguntar ao gestor sobre o processo de criação das Academias a Céu Aberto, houve a seguinte resposta:

Iniciou-se todo esse pensamento na verdade através do Governo do Estado, que criou a "Ginástica para Todos", o Programa nasceu no governo e ele colocava à disposição dos Municípios esses equipamentos ao ar livre. Então, dentro dessa proposta algumas academias foram cedidas para Belo Horizonte, e isso aconteceu em 2010, onde foram instaladas apenas 2 academias em Belo Horizonte. Em 2011, quando eu entrei assumindo o cargo que eu exerço hoje, e a partir dessa história nós tínhamos outras academias em estoque, onde a gente promoveu a instalação dessas academias em outros locais. Então a gente pegou essa proposta que tinha sido iniciada pelo Governo de Estado, fizemos estudos de outros equipamentos que poderiam trazer outros benefícios que as outras não trariam, então é essa equipe de analista, que são profissionais da área de Educação Física, sentaram pra justamente ajustar alguns equipamentos, os quais hoje são utilizados em todas as licitações que a gente opera (ENTREVISTADO SMAL, 2015).

A partir disso, mesmo não sendo exposto no site da Prefeitura de Belo Horizonte, é possível perceber que tal iniciativa começou com uma política do Governo de Minas Gerais sendo executada pela Subsecretaria de Esportes ${ }^{9}$. Assim, a criação das

\footnotetext{
7 As Academias da Cidade funcionam em vários pontos da cidade, normalmente nos Centros de Referência e Assistência Social (CRAS). Essas academias funcionam de segunda a sábado, em horários variados, na parte da manhã, tarde e noite. As atividades são gratuitas e qualquer pessoa, preferencialmente acima de 18 anos, pode participar das mesmas, basta preencher o cadastro e fazer a avaliação física com o professor.

${ }^{8}$ Disponível em: https://prefeitura.pbh.gov.br/esportes-e-lazer/academia-ceu-aberto. Acesso em: 23 nov. 2020.

${ }^{9}$ Disponível em: http://social.mg.gov.br/esportes/academias-ao-ar-livre-e-kits-esportivos. Acesso em: 23 nov. 2020
} 
Academias a Céu Aberto se deu a partir de uma política pública já existente no estado, sendo denominada de Academia ao Ar Livre.

Ao perguntar sobre quais as normativas básicas que expressam as finalidades das Academias a Céu Aberto e se há um documento que apresenta os princípios, objetivos e diretrizes do Programa, o gestor respondeu o seguinte:

Sim existe o projeto, o projeto existe internamente, tem até no site da prefeitura, se você entrar lá academia, tem dizendo o que é, qual o objetivo, qual que é objetivo geral e o específico, qual a metodologia de trabalho, isso tem, ele não é normatizado, como, por exemplo, uma educação da escola, onde existe uma legislação local. A academia não tem isso, tem o projeto, tem tudo internamente, tudo é criado, tudo é pensado, tem quais são os itens, porque pensou-se naquele item, porque pensou-se no outro, porque não trouxe aquele, porque o equipamento tem que ficar na praça (ENTREVISTADO SMAL, 2015).

Percebe-se que há um objetivo e locais pensados para a instalação das Academias a Céu Aberto, entretanto, quando solicitado acesso aos documentos formais da política, não é possível, pois não há um projeto sistematizado em si. Mesmo que as ideias estejam claras sobre o que constitui as Academias a Céu Aberto, um aparato sobre o plano de implementação da política fortalece sua compreensão, valorização e possíveis consultas para se pensar a gestão em outros locais e em sua continuidade ao longo de outros governos.

As diretrizes gerais de uma política de lazer, de acordo com Carvalho (1977), não podem se restringir apenas a uma política de atividades, mas contemplar também questões relativas à formação e ao desenvolvimento de quadros para atuação, aos espaços e aos equipamentos a serem implementados, à cultura local, ao acesso, entre outros aspectos, para que assim projetos não sejam rebatizados e tenham um ciclo pequeno na política.

Em relação ao "por quê” as Academias a Céu Aberto foram inseridas na agenda da antiga Secretaria Municipal Adjunta de Lazer o gestor apontou que, 
cidade. Então dentro da política de esporte, porque ela tem um caráter esportivo, dentro da política de saúde, porque ela visa um melhor condicionamento, então automaticamente uma melhora na circulação sanguínea, e isso uma disposição melhor para as pessoas e ao mesmo tempo a gente começou a definir assim, porque uma política de lazer (ENTREVISTADO SMAL, 2015).

Ao pesquisar sobre o Programa no site de Avaliação dos Resultados de políticas públicas de Belo Horizonte (SISTEMA BH METAS E RESULTADOS, 2015 ${ }^{10}$ ), foi constatado que a Academia a Céu Aberto era vinculada à política de promoção de esporte e lazer na cidade. Além disso, no Plano Estratégico de Belo Horizonte (PEBH, 2016) ${ }^{11}$, houve como resultado diversos Projetos Sustentadores relacionados à temática. De acordo com o documento, o Projeto Sustentador "Promoção do Esporte e do Lazer" consiste em promover o acesso aos serviços públicos de esporte e lazer, por meio da ampliação do atendimento e da requalificação de equipamentos, fomentando práticas esportivas e de lazer, tendo-se como meta física a implantação das Academias a Céu Aberto.

Ainda no PEBH foi verificado que, em princípio, as Academias a Céu Aberto estariam sob a responsabilidade da Secretaria Municipal de Políticas Sociais, porém, como já mencionado, no ano de 2015, o Programa era gerenciado pela Secretaria Municipal de Esporte e Lazer (SMEL), especificamente pela Secretaria Municipal Adjunta de Lazer.

As fontes documentais coletadas em 2020 indicam que, com a junção do esporte e do lazer em uma única Secretaria Adjunta de Esporte e Lazer pertencente à SMEL, as

\footnotetext{
${ }^{10} \mathrm{O}$ BH Metas e Resultados objetiva uma maior eficácia nas ações, políticas urbanas e sociais e em todos os serviços públicos prestados pela Prefeitura. Disponível em: https://bhmetaseresultados.pbh.gov.br /content/promo\%C3\%A7\%C3\%A3o-do-esporte-e-do-lazer.

${ }^{11}$ O Plano Estratégico de Belo Horizonte (PEBH) foi criado sob o discurso da necessidade de maior eficácia da gestão pública e da construção de um planejamento a longo prazo para a capital mineira. $\mathrm{O}$ documento estabeleceu objetivos estratégicos e metas de curto, médio e longo prazo e é composto pelas Áreas de Resultado (definidas com o intuito de orientar os esforços do Executivo, visando transformações sociais, econômicas, ambientais e institucionais) e, para cada uma delas, projetos específicos denominados Projetos Sustentadores (contendo objetivos específicos, população beneficiada, indicadores, prazos para implantação, órgãos e equipes responsáveis, etc.). Disponível em: https://bhmetaseresultados.pbh.gov.br/content/planejamento-estrat\%C3\%A9gico-2030.
} 
Academias a Céu Aberto passaram ser de responsabilidade exclusiva da Diretoria de Infraestrutura Esportiva e de Lazer (DIEL) que coordena, por sua vez, a Gerência de Controle e Manutenção de Equipamentos Esportivos (GCMAE) e a Gerência de Engenharia e Supervisão de Projetos (GESUP) ${ }^{12}$.

Vale adendo de que a Secretaria Municipal Adjunta de Lazer, responsável pelas Academias a Céu Aberto, era um órgão relativamente recente, criado em 2011 pelo Decreto $\mathrm{n}^{\circ} 14.621$, de $1^{\circ}$ de novembro, e extinto (ao fundir-se ao esporte) em 2017 na gestão do atual prefeito de Belo Horizonte. Estudos específicos sobre a junção desses órgãos seriam necessários para mensurar se essa modificação na estrutura burocrática foi benéfica (ou não) para o desenvolvimento das políticas de lazer da cidade.

Existem debates que indicam que a existência de muitas pastas gerenciais acarreta uma destinação incipiente de verba a cada uma, além do número de servidores não suprir a demanda. Não obstante, parte da literatura que se debruça sobre as políticas públicas de lazer compreendem que se ter uma pasta própria - como no caso de Belo Horizonte, uma Secretaria Municipal Adjunta de Lazer - configura um passo primordial para se pensar o que compõe e quais os objetivos do município ao oferecer e garantir esse direito à população.

No caso das Academias a Céu Aberto arrisca-se dizer que o fato desse Programa ter saído da responsabilidade de uma Secretaria Municipal Adjunta de Lazer responsável, dentre outros, por desenvolver e conduzir o processo de planejamento, de execução, de monitoramento e de avaliação da política municipal para a cultura do lazer em espaços públicos, visando estimular o acesso da população aos bens culturais e de lazer ${ }^{13}$, para a responsabilidade de uma Diretoria de Infraestrutura (ainda que de

\footnotetext{
12 Disponível em: http://prefeitura.pbh.gov.br/sites/default/files/estrutura-de-governo/esportes-elazer/imagens/ORG_SMEL.pdf. Acesso em: 23 nov. 2020.

13 Decreto $\mathrm{n}^{\mathrm{o}}$ 14.621, de $1^{\circ}$ de novembro de 2011. Disponível em: Decreto 14.621, 2011, de Belo Horizonte MG (leismunicipais.com.br). Acesso em: 20 nov. 2020.
} 
esporte e lazer), aparenta representar um retrocesso para o planejamento e execução dessa política. Supostamente uma Diretoria de Infraestrutura, ou seja, uma diretoria técnica, de controle, de manutenção e de implantação, não abarca na totalidade a constituição uma política pública, levando em consideração as fases de implementação e gestão (que serão melhor elucidadas adiante).

Para melhor entender o "porquê" das Academias a Céu Aberto serem vistas como política de lazer na Prefeitura de Belo Horizonte, seguem as concepções de lazer que o gestor apontou ao longo da entrevista:

Então, pensando nessa política de lazer, que aqui é caracterizada como uma política de lazer, que não é uma coisa que visa rendimento, um crescimento muscular, visa sim uma melhora na circulação sanguínea e nas articulações. É uma política pública que foi traçada justamente pela questão do sedentarismo, as pessoas estão engordando, estão envelhecendo, hoje a população está mais envelhecida, então a gente pensa na questão do envelhecimento mais saudável (ENTREVISTADO SMAL, 2015).

Porque quando eu falo assim da discussão, a gente percebe que hoje há uma grande parcela da população que está ociosa e está sem realizar atividade física, e a gente começou a perceber também que o alto custo das academias poderia está gerando também a falta desses exercícios diários, e as pistas de caminhada, os locais assim abertos da cidade, como praças, parques, cada vez estão mais cheios e as pessoas fazendo atividades como caminhada e a corrida, que hoje você sabe que é o esporte mais barato que existe, né, um tênis, um short e uma camisa (ENTREVISTADO SMAL, 2015).

De acordo com a fala do entrevistado o lazer foi relacionado ao "não rendimento", à "saúde", à "não obrigação", ao "sedentarismo", ao "alto custo das academias particulares" e ao "baixo custo de se praticar uma atividade ao ar livre". Esses motivos levam a entender que as políticas de lazer dessa Secretaria possuíam esse mesmo viés de entendimento sobre o lazer, visto como uma relação simples entre "saúde" e "não obrigação".

A Academia a Céu Aberto é considerada como uma política de lazer, porém seria interessante que os gestores justificassem tal escolha com respostas que não visem somente o "contrário ao esporte de rendimento" e uma "solução para a saúde da sociedade", pois esses conceitos e concepções estão em constante debate na comunidade 
acadêmica e merecem uma concepção ampliada do meio político, quando se propõe a implementar políticas públicas. Conforme Amaral (2014), mesmo que não haja um consenso em torno de uma definição de lazer na literatura, isso não significa que os atores políticos não devam buscar legitimidade nessa área para garanti-lo como direito e como política pública.

Na pesquisa de Silva et al. (2019), sobre o Orçamento Municipal de Belo Horizonte entre os anos de 2014 e 2017, apesar da compreensão ampliada acerca do esporte e do lazer, tem-se que a maior alocação de verba em programas que tratam diretamente sobre esses fenômenos foi direcionada à ampliação do Programa Academias a Céu Aberto, bem como para aquisição e manutenção desses equipamentos, deixando de lado as ações que incluem a animação cultural e apropriação social desses locais.

Apropriar-se do direito ao lazer não significa apenas garantir espaços e equipamentos, dias, horários, e acesso a alguns programas oferecidos pelo poder público, com atividades definidas, a partir de discursos demagógicos. De acordo com Bramante e Pina (2016), uma interpretação equivocada da utilização dos espaços para o esporte e o lazer é considerar que estes podem funcionar sem qualquer forma de gestão: "basta colocar o espaço à disposição das pessoas que tudo estará equacionado e resolvido" (p.08).

Segundo os autores, existe uma série de procedimentos de gestão, comuns aos espaços específicos, não-específicos e aos espaços naturais de uso aparentemente espontâneo, que vão desde o planejamento e construção ou organização do espaço, até a definição de uma "política de animação" (MARCELLINO, 1996, p.32), como por exemplo: estruturação dos recursos humanos, materiais e financeiros necessários para administrar e animar os espaços; elaboração da programação das atividades, programas, 
projetos, eventos e ações; divulgação à população atendida; e a execução das atividades (BRAMANTE; PINA, 2016).

Outro ponto que provoca discussão e foi revelado pelos dados acerca da gestão das Academias a Céu Aberto se refere a sua distribuição na cidade. De acordo com o Plano Estratégico (PEBH, 2016), Projeto Sustentador “Esporte e Lazer”, em 2013 foram adquiridas 260 Academias a Céu Aberto com recursos municipais e também mais 75 foram adquiridas com recursos oriundos de convênio firmado com o estado e a União. Em 2013, foram instalados 143 conjuntos; em 2014, foram instalados 108 e, em 2015, foram instalados mais 54, totalizando 354 Academias a Céu Aberto instaladas nas nove regionais da cidade até o ano de 2016.

\footnotetext{
A meta da academia é atender todos os bairros de Belo Horizonte. Hoje, por exemplo, nós traçamos uma meta, um raio de $500 \mathrm{~m}$ para cada academia, então hoje nós temos 452 bairros já dentro do raio, faltam 35 bairros pra gente poder alcançar essa meta de todos os bairros estarem dentro desse raio de $500 \mathrm{~m}$. Tem um mapa interativo da pra você perceber que a gente tentou distribuir a academia de forma uniforme pela cidade, é lógico que vai ter algumas regiões e alguns bairros que vão ter mais academias que outros, pela questão do número da população, ou até mesmo pelo tamanho daquele bairro, e outros não vão ter porque não tem condições físicas, não tem um espaço público e adequado para receber os equipamentos (ENTREVISTADO SMAL, 2015).
}

Como é possível identificar na fala do gestor e em consonância com informações disponíveis no site da PBH, a previsão era de que, até o final de 2016, fossem instaladas 492 academias na cidade, para que cada bairro passasse a ter pelo menos uma. Entretanto, as fontes documentais coletadas em 2020 indicam a existência de apenas 423 Academias a Céu Aberto em Belo Horizonte distribuídas pelas regionais, conforme indicado na Tabela 1. Ou seja, quatro anos após a meta estabelecida pelo cronograma de ampliação, ainda falta a instalação de 69 Academias a Céu Aberto. 
Tabela 1: Relação do número de Bairros e do número de Academias a Céu Aberto (ACA) existentes em Belo Horizonte de 2016 a 2020.

\begin{tabular}{|l|c|c|c|c|}
\hline \multicolumn{1}{|c|}{ Regionais } & $\mathbf{N}^{\mathbf{0}}$ de Bairros & $\mathbf{N}^{\mathbf{0}}$ ACA em 2016 & $\mathbf{N}^{\mathbf{0}}$ ACA em 2020 & \% Ampliação \\
\hline Barreiro & 74 & 47 & 55 & $74,32 \%$ \\
\hline Centro-Sul & 49 & 34 & 40 & $81,63 \%$ \\
\hline Leste & 48 & 46 & 51 & $106,25 \%$ \\
\hline Nordeste & 71 & 48 & 55 & $77,46 \%$ \\
\hline Noroeste & 56 & 30 & 48 & $85,71 \%$ \\
\hline Norte & 46 & 32 & 42 & $91,30 \%$ \\
\hline Oeste & 71 & 40 & 41 & $57,74 \%$ \\
\hline Pampulha & 64 & 42 & 55 & $85,93 \%$ \\
\hline Venda Nova & 42 & 35 & 36 & $85,71 \%$ \\
\hline Total & $\mathbf{4 8 7 *}$ & $\mathbf{3 5 4}$ & $\mathbf{4 2 3}$ & \\
\hline
\end{tabular}

* 14 Bairros estão divididos entre mais de uma regional. Portanto, 487 é o número total de bairros de Belo Horizonte, sem considerar repetições de bairros compartilhados em mais de uma regional administrativa.

Fonte: Prefeitura de Belo Horizonte Disponível em: https://prefeitura.pbh.gov.br/esportes-elazer/academia-ceu-aberto. Acesso em: 23 nov. 2020.

Como indicado na última coluna da Tabela 1, a grande maioria das regionais ultrapassou a média de $60 \%$ para o cumprimento da meta. Entretanto, apesar de aparentemente ser um indicador positivo, percebe-se a existência de regionais que já extrapolaram o número de Academias, como é o caso da regional Leste (106,25\%), e outra que ainda não chegou nem na média de bairros atendidos, regional Oeste $(57,74 \%)$. Cabe adendo de que não é problema uma regional ter mais Academias por bairro, mas, uma vez que a grande maioria das regionais ainda possuem bairros sem esse Programa, a distribuição das novas Academias poderia ter ocorrido de forma mais igualitária.

Para além do não cumprimento total da meta física, pode-se dizer que - se comparado à 2016 onde houve uma distribuição uniforme de Academias a Céu Aberto 
na cidade em relação às regionais (ABADE, 2016) - o mesmo não ocorreu após a implementação do cronograma de ampliação, verificado pelos dados obtidos em 2020.

Em 2016 as regionais Nordeste e Barreiro eram as que possuíam maior número de Academias implementadas, 48 e 47 respectivamente. Até 2020 essas regionais mantiveram o posto ao receber 07 (Nordeste) e 08 (Barreiro) novas Academias, totalizando 55 Academias a Céu Aberto em cada regional (77,46\% e 74,32\%).

As regionais Noroeste e Norte eram as que, em 2016, possuíam o menor número de equipamentos, 30 e 32, respectivamente. Até 2020 receberam 18 (Noroeste) e 10 (Norte) novas Academias, deixando os postos assumidos anteriormente, e ficando com 48 na regional Noroeste $(85,71 \%)$ e 42 na regional Norte $(91,30 \%)$. Tais dados parecem indicar que houve uma ação planejada no sentido de implementar o cronograma de ampliação das Academias a Céu Aberto nas regionais menos favorecidas anteriormente.

Entretanto, ao mesmo tempo, tem-se como exemplo os casos das regionais Oeste e Venda Nova que receberam apenas 01 novo equipamento ao longo desses quatro anos, mesmo sendo esta última (Venda Nova) a terceira regional com menor número de Academias implementadas em 2016 - tinha 35 e passou a ter 36 em 2020 (85,71\%). Como demonstrado anteriormente, a regional Oeste é a única que não atingiu $60 \%$ da meta de Academias instaladas.

Ademais, a Pampulha, regional que já possuía 42 Academias a Céu Aberto, um dos maiores números se comparado às demais regionais em 2016, recebeu até 2020 a instalação de 13 novos equipamentos, empatando com as regionais Nordeste e Barreiro que possuem mais academias, 55 no total $(85,93 \%)$.

Ao acessar o site da gestão compartilhada da Prefeitura de Belo Horizonte ${ }^{14}$, há um mapa interativo que contém o local de todas as Academias a Céu Aberto em cada

\footnotetext{
$14 \quad$ Disponível em: https://bhmaphm.pbh.gov.br/v2/mapa/idebhgeo\#zoom=1\&lat=7798918.72721\&lon=611690.52305\&baselayer=base \&1
} 
regional, além de apresentar os demais serviços que podem ser consultados pelos cidadãos. Entretanto, o conjunto de informações colhidas não ofereceram indícios que indicassem as maneiras e estratégias de ampliação do Programa, o porquê de algumas regionais serem preteridas e a disparidade entre elas (algumas regionais recebendo 18 novas Academias, ao passo que outras receberam apenas 01 novo equipamento).

Por fim, o conjunto dos documentos analisados não permite inferir também sobre a distribuição desses equipamentos dentro de cada regional, ou seja, em cada bairro. O que pode acontecer é a centralização das Academias em alguns locais específicos, corroborando com Abade (2016). Esta informação configura um dado importante de ser levantado, uma vez que, segundo Marcellino (1987), existem diversas barreiras socioculturais verificadas no lazer (de gênero, de faixa etária, de espaços e equipamentos, de estereótipos, de acesso), intra e interclasses sociais, que limitam o lazer qualitativa e quantitativamente à população. Esse fato requer atuação do poder público no sentido de minimizar seus efeitos e de modo a priorizar ações que facilitem o acesso às camadas da população que, normalmente, são negligenciadas.

Em relação à faixa etária dos usuários, segundo dados do site da Prefeitura de Belo Horizonte, as Academias a Céu Aberto visam proporcionar condições adequadas para a prática de atividades físicas para pessoas de todas as idades, mas o público alvo, prioritariamente, é o da terceira idade. Fato corroborado por uma pesquisa publicada em 2019 ${ }^{15}$, que objetivou analisar essa política pública, considerando o que pensam os frequentadores das Academias a Céu Aberto sobre o papel desempenhado no seu lazer e na sua saúde (AMORIM; LEMOS; COUTO, 2019). Ao todo a pesquisa englobou 376 participantes, de ambos os sexos, frequentadores de 48 diferentes Academias na cidade

ayers=academia_ceu_aberto $\% 2$ Ccampo_futebol $\% 2 \mathrm{Ccamp} \_$fut_society $\% 2 \mathrm{Cginasio} \% 2 \mathrm{Cpista}$ skate $\% 2 \mathrm{Cq}$ uadra\%2Cquadra_poliesportiva.

${ }^{15}$ Pesquisa realizada pelo Grupo de Estudo de Sociologia, Pedagogia do Esporte e Lazer (GESPEL), da Escola de Educação Física, Fisioterapia e Terapia Ocupacional da Universidade Federal de Minas Gerais (EEFFTO/UFMG). 
de Belo Horizonte. Destes, 44,1\% responderam ter acima de 60 anos e 26,32\% na faixa etária de 50 a 59 anos. Tais dados são corroborados pela fala do gestor, e estão em consonância com os achados da pesquisa de Abade (2016).

\begin{abstract}
Então a gente pede a orientação para acima de 12 anos, mas ela pode ser praticada por qualquer faixa etária. Porque a gente faz assim, hoje nós temos um público maior da terceira idade, pessoas acima de 50 anos, porque muitas as vezes são as pessoas que ainda não procuraram as academias, a grande parcela ainda não conseguiu entrar, não foi absorvida pelas academias particulares, por isso então a gente colocou um equipamento que seria adequado para esse público, que estava sedentário em casa, que não estava se exercitando de maneira adequada, não estavam fazendo as atividades de lazer, que naquele momento a gente identificou que seria o público que a gente deveria atender, seria mais a questão dos idosos (ENTREVISTADO SMAL, 2015).
\end{abstract}

O estudo de Amorin; Lemos e Couto (2019), tece algumas aproximações teóricas entre a faixa etária "acima dos 60 anos" com umas das perguntas que realizaram aos participantes sobre "por que você frequenta a academia". O termo "terceira idade" foi recorrente como motivo para frequentarem a Academia, de tal maneira que as respostas relacionavam a "necessidade da terceira idade de fazer atividade física" à "melhoria da saúde" e à "continuidade em fazerem o que gostam".

Abade (2016), ao aplicar um questionário semiestruturado, contendo questões abertas e fechadas, aos frequentadores das Academias a Céu Aberto constatou ainda a necessidade de uma orientação profissional nesses locais. Dos 243participantes da pesquisa $224(92,18 \%)$, em três diferentes Academias a Céu Aberto, responderam "sim" à pergunta sobre a "necessidade da presença de um professor de Educação Física" nesses espaços.

Entre os relatos registrados pela autora destacam-se a falta de um instrutor "porque muita gente faz os exercícios e não sabe o efeito devido à falta de informação", as dúvidas sobre "qual a frequência de utilização", sobre "os exercícios corretos", para "quais partes do corpo" e também para "não prejudicar a saúde" ou "estragar os aparelhos" (ABADE, 2016, p. 97). 
A Prefeitura de Belo Horizonte (PBH) disponibiliza nas Academias a Céu Aberto algumas placas com indicativos de uso, alongamentos e informação sobre a proibição de uso por crianças. Essas placas instrutivas são colocadas junto aos equipamentos, mas em diversos locais estão pichadas ou quebradas, dificultando a visualização pelos frequentadores.

De acordo com Abade (2016), a presença de profissionais capacitados pode favorecer o uso, uma vez que, mesmo o equipamento sendo planejado para não proporcionar lesão aos usuários e sendo de fácil acesso, os frequentadores possuem dúvidas e não existem pessoas orientadas a ajudá-los.

Pelos registros da autora, a PBH oferecia a orientação de profissionais de forma esporádica. Existia um quadro técnico de analistas de políticas públicas, composto por Profissionais de Educação Física, que visitavam uma Academia a Céu Aberto por dia, a fim de sanar algumas dúvidas, por meio de um programa denominado "Lazer + Saúde" (ABADE, 2016). Entretanto, atualmente, as fontes documentais coletadas não apresentam indícios dessas intervenções. Se antes eram esporádicas, ao que tudo indica, hoje já não existem.

No site da $\mathrm{PBH}$ os programas/projetos que aproximam dessa intervenção profissional junto à população são o "Projeto Caminhar", com orientações e avaliações físicas em cidadãos de diferentes faixas etárias em pistas de caminhadas, e o "Vida Ativa", que realiza atividades mensalmente para a comunidade acima dos 50 anos em 48 núcleos regionalizados ${ }^{16}$. Pode ser que instrutores desses outros programas da SMEL, (como Vida Ativa, Caminhar e BH Cidadania) utilizem também as Academias como ponto para suas atividades, mas as fontes documentais não fizeram nenhuma

\footnotetext{
${ }^{16}$ Disponível em: https://prefeitura.pbh.gov.br/esportes-e-lazer.
} 
menção sobre intervenções profissionais diretas nas Academias a Céu Aberto ou ao Programa "Lazer + Saúde".

No que diz respeito às políticas públicas de lazer, Melo e Peres (2003) elencam diferentes fatores para garantir a qualidade de acesso aos equipamentos, dentre eles está a compreensão dos significados e da importância de determinada manifestação cultural ou equipamento de lazer por parte da população, a partir de uma intervenção pedagógica no sentido de que as pessoas sejam estimuladas a utilizar de maneira adequada o equipamento. Segundo os autores, é por meio dessas características que os indivíduos estabelecem uma relação de forma de uso, valorização do espaço e coletividade.

Quanto aos custos de implementação desse Programa, segundo Abade (2016), cada Academia a Céu Aberto possui um custo médio de $\mathrm{R} \$ 25.000,00$. Conforme informações das Secretarias Regionais da Cidade, o custo de implantação tem uma média de $\mathrm{R} \$ 5.000,00$, sem contar com obras estruturais. O custo de manutenção é em torno de $\mathrm{R} \$ 500,00 /$ mês por Academia. Para instalação e manutenção dos equipamentos, neste primeiro momento, a extinta SMAL buscou parcerias com as Secretarias Regionais, responsabilizando-as para esta função, conforme a disponibilidade do serviço.

No caso aqui hoje a Secretaria Municipal de Esporte e Lazer para instalar as academias conta muito com o apoio das regionais. Então Belo Horizonte é dividida por 9 regionais e todas são parcerias nesse momento de instalação, até mesmo atualmente realizam a manutenção desses equipamentos (ENTREVISTADO SMAL, 2015).

Para ajudar nesse custo a SMAL realizou parcerias com alguns deputados, como é o caso do então deputado estadual Marque Batista Abreu (PTB - PARTIDO TRABALHISTA BRASILEIRO). Com essa parceria houve a instalação de várias Academias a Céu Aberto nos bairros da capital mineira, a emenda destinada para o projeto foi de $\mathrm{R} \$ 1$ milhão de reais. Outros deputados estaduais, como Celinho do Sinttrocel (PCdoB - PARTIDO COMUNISTA DO BRASIL), João Vitor Xavier (PSDB 
- PARTIDO DA SOCIAL DEMOCRACIA BRASILEIRA), Luzia Ferreira (PPS - atual CIDADANIA), Mário Henrique (PCdoB - PARTIDO COMUNISTA DO BRASIL), Paulo Lamac (PT - PARTIDO DOS TRABALHADORES), também estavam na lista, além do deputado federal Luiz Tibé (PTdoB - atual AVANTE). Essas emendas foram emitidas em contratos no ano de 2011, 2012 e 2014. O gestor esclareceu sobre a verba de financiamento das Academias a Céu Aberto:

\begin{abstract}
Alguns deputados tiveram interesse em colocar as emendas parlamentares para que fossem direcionadas para a compra desses equipamentos, vendo a grande proporção da população, a grande participação e o grande número de pedidos que a gente tinha. Há o recurso também do tesouro, quer dizer da própria Prefeitura, e também foram colocados mais de 4 milhões de reais para comprar equipamentos" (ENTREVISTADO SMAL, 2015).
\end{abstract}

Ao comentar sobre a possibilidade de parceria com o Governo Federal, o gestor afirma que não existia nenhuma parceria com a Prefeitura no ano de 2016 e salienta que, pelo Ministério da Saúde, poderia haver um recurso vinculado a outro tipo de Academia, mas não às Academias a Céu Aberto de Belo Horizonte.

Em relação à escolha dos locais de implantação do Programa, foi levada em consideração a revitalização de espaços ociosos e degradados em alguns bairros.

É sempre atendido aqueles lugares que tem maior vulnerabilidade, depende do mínimo de estrutura possível, porque não precisa fazer um barranco de contenção, não tenha muitas vezes que destruir algum equipamento, tipo assim algum prédio, então quer dizer, procura-se também atender dessa forma, um mínimo de obra possível. E um lugar de fácil acesso para todos, não adianta colocar em frente a sua casa onde não tem uma estrutura, um passeio pequeno, ou uma pracinha muito pequena, onde não comporta, então a gente também dá esse feedback, olha infelizmente a praça para instalar uma academia precisa no mínimo de $150 \mathrm{~m}^{2}$ e essa praça tem $100 \mathrm{~m}^{2}$, então não comporta o equipamento (ENTREVISTADO SMAL, 2015).

Não foi encontrado nenhum relatório sistematizado sobre as Academias a Céu Aberto, a pesquisa contou com o acesso somente ao documento denominado "Registro de Atendimentos". Neste formulário, havia perguntas em relação às características físicas dos equipamentos, à visibilidade, à conservação e ao fluxo de pessoas. Devido ao grande número de Academias a Céu Aberto na cidade, nem todas são visitadas ao longo 
do ano. Além disso, acredita-se que tal instrumento não seja eficiente na avaliação de uma política por parte daqueles que a utilizam, uma vez que desconsidera dados qualitativos que podem subsidiar uma melhor gestão e interlocução com os usuários.

Quando perguntado sobre as formas de monitoramento e avaliação da política, o gestor respondeu:

Bom, eu acho que está tendo sim um acompanhamento e monitoramento muito bacana, porque primeiro a gente realiza através dos nossos profissionais, porque eles rodam as academias, então eles fazem o acompanhamento de toda atividade, se está sendo bem movimentada, se não está sendo, então a gente tem que ter registro, ele vai lá fala quantas pessoas estão lá na academia. A gente tem avaliação estrutural, mesmo que venha através de denúncia, mas muitas vezes, a regional passa lá e dá sua manutenção diária. Além, lógico, das ligações telefônicas, pessoas ligando, olha o equipamento sumiu aqui, alguém roubou, alguém quebrou, a gente recebe bastante ligação disso também. Então, acho que assim, de lazer para as Academias a Céu Aberto é uma política muito boa e já está trazendo resultado e a tendência dela é crescer (ENTREVISTADO SMAL, 2015).

Segundo Amaral (2014), a “avaliação de políticas públicas tem apresentado grande expansão, em especial a partir da década de 1990, no contexto da reforma do Estado brasileiro" (p. 150). Tinôco; Souza e Oliveira (2011) indicam que há um predomínio de modelos avaliativos inspirados no positivismo, ligados à denominada avaliação gerencialista. Os autores afirmam que essa avaliação apresenta "muitos problemas e dificuldades, pois nem sempre os elementos indispensáveis à sua concretização, como a definição dos objetivos que se quer alcançar com a política, estão disponíveis para guiar a apreensão e julgamento dos efeitos e do impacto da política" (TINÔCO; SOUZA; OLIVEIRA, 2011, p. 31). Esse monitoramento e avaliação qualitativa (e não somente quantitativa) proporciona um diagnóstico da operacionalização e do plano de formulação da política de forma completa, fazendo parte do presente e do futuro de uma política pública. Ao ser indagado sobre o futuro dessa política, o gestor responde:

Olha eu vou te falar a verdade é muito difícil de falar na política de como vai ser se houver uma troca ou não de Prefeito, mas que a experiência de BH está sendo bem bacana. E eu acho que a tendência de continuar, se tiver mudança 
ou não de governo, é porque os outros Municípios estão procurando, BH está sendo referência. Todo mundo vem vendo bom resultado, essa questão de viabilizar para a população uma prática de atividade física de forma gratuita de fácil acesso, quer dizer, está pegando em todo Brasil (ENTREVISTADO SMAL, 2015).

A tendência agora é de finalizar o processo de atender todos os bairros e aí vem a questão da melhora do programa, a gente ter uma manutenção adequada, através dos parceiros, dos adotantes, então ter um recurso específico pra isso, onde a gente consiga dar condições a todas as academias estarem em pleno funcionamento (ENTREVISTADO SMAL, 2015).

Essa fragilidade de não saber se a política irá continuar refere-se ao fato das Academias a Céu Aberto em Belo Horizonte serem políticas de governo. De acordo com Santos e Amaral, “essa provisoriedade das políticas públicas de lazer, é decorrente do fato de elas serem políticas de governo e não de Estado, e isso expressa o lugar ocupado por ele (lazer) na sociedade e evidencia o seu desenvolvimento no atual momento" (SANTOS, AMARAL 2010, p. 7).

Um esforço na gestão das Academias a Céu Aberto em manter a continuidade e, principalmente, a manutenção desses equipamentos, foi materializado através do Decreto $\mathrm{n}^{\mathrm{o}} 15.795$, de 09 de dezembro de 2014, e estabelece normas e procedimentos para parcerias entre o Município de Belo Horizonte e a sociedade, no que concerne à adoção de Academias a Céu Aberto. O objetivo do decreto foi estabelecer parcerias com a sociedade civil e com as empresas para realizarem manutenção preventiva, corretiva e reforma desses equipamentos que se encontram em todas as regionais da cidade. $\mathrm{O}$ adotante teria a responsabilidade legal de zelar pelo equipamento adotado, conforme o edital, e impedir falhas no desempenho dos mesmos, por meio de lubrificação, ajustes, higienização e limpeza, além de outras ações, como substituição de peças, acessórios, soldas, retoques e pintura. Em contrapartida, o responsável poderia afixar no local uma placa publicitária de identificação que leve sua logomarca ou a assinatura do responsável, de acordo com as normas estabelecidas no decreto. As propostas tiveram o 
prazo de entrega no final de 2015 e, até a presente data, as fontes documentais não indicaram o início dessa parceria.

É, o Adote uma Academia é um projeto o qual a gente tem uma esperança aí que $90 \%$ das academias sejam adotadas né, e que seja um grande boom assim no sentido de vida para as academias, porque a partir do momento que a empresa coloca a marca dela, talvez ela queira impulsionar ainda mais, quer levar as pessoas até lá (ENTREVISTADO SMAL, 2015).

Adoção pode acontecer desde a pessoa física até o jurídico de grande porte, ela pode ser feita por uma ou mais empresa simultaneamente, se quiser eu e mais uma empresa uma mesma academia é só fazer dentro do tamanho exato lá da logomarca, colocar as duas lá, só não pode ultrapassar aquele espaço, e se tiver 20 logomarcas lá não tem problema. É ideal que o equipamento esteja disponível de forma adequada para a utilização dos usuários (ENTREVISTADO SMAL, 2015).

Acredita-se que esse decreto busca possibilitar a manutenção das Academias a

Céu Aberto e a continuidade da política, entretanto, percebe-se também que é passada a responsabilização do cuidado dos equipamentos para a sociedade, em específico às empresas, como forma de suprimir uma fragilidade da gestão pública e do seu financiamento.

\section{Conclusão}

O objetivo do presente artigo foi apresentar e discutir os dados acerca das Academias a Céu Aberto, a partir da visão de um dos gestores dessa política e das diretrizes da Secretaria Adjunta de Esporte e Lazer de Belo Horizonte/MG.

Para tanto, considerou-se o ordenamento institucional do setor, as condições de estrutura física para a gestão e para o desenvolvimento do programa, o quadro pessoal envolvido nos diferentes níveis de planejamento e execução, e por fim, os recursos financeiros para implementação do Programa.

As Academias a Céu Aberto são compreendidas como uma política de lazer por parte do município, mas este foi relacionado ao não rendimento, a não competitividade, à saúde, à não obrigação, ao sedentarismo, ao alto custo das academias particulares e ao 
baixo custo de se praticar uma atividade ao ar livre, evidenciando uma concepção restrita desse fenômeno e impactando nas formas de gestão do Programa.

O principal órgão responsável atualmente pela Academia a Céu Aberto é a Secretaria Municipal de Esporte e Lazer (SMEL), por meio da Diretoria de Infraestrutura Esportiva e de Lazer (DIEL). Não existe uma política de animação desses espaços, com direcionamento de profissionais capacitados para atenderem as demandas da população (em sua maioria idosos) e as principais ações são voltadas à implantação e manutenção dos equipamentos.

Apesar desse foco na implantação, ainda não foi cumprida a meta física estipulada para o final de 2016 de instalar 492 Academias na cidade, para que cada bairro passasse a ter pelo menos uma unidade. E além disso, nos últimos quatro anos a distribuição desses equipamentos se deu de forma desigual entre as regionais.

Com um alto custo de implantação e manutenção, a extinta SMAL buscou parcerias com as Secretarias Regionais e com a sociedade (por meio do Adote uma Academia) visando manter e dar continuidade ao Programa. Entretanto, percebe-se uma desresponsabilização por parte da Prefeitura ao delegar à sociedade (em específico às empresas privadas), os cuidados de manutenção dos equipamentos, evidenciando uma fragilidade da gestão pública e do seu financiamento.

Por fim, as falas do Gestor e o conjunto das fontes documentais evidenciam que, apesar de serem compreendidas como uma política pública de lazer, as ACA atualmente correspondem apenas à dimensão de infraestrutura. Não existem normativas claras em relação aos objetivos da política, a mesma tem se mantido apenas por meio da manutenção e implantação de novos equipamentos, não existe também um monitoramento das ações o que pode interferir na sua gestão. 
Acredita-se que só a construção de equipamentos não seja uma solução para promoção do esporte e do lazer como direitos constitucionais, a sua gestão e acompanhamento por partes de profissionais capacitados é fator primordial para proporcionar um caminho de sucesso e uso dessas políticas. Sendo assim, esse artigo auxiliou no entendimento do que realmente é proposto e o que vem sendo implementado pelo Programa Academia a Céu Aberto, contribuindo para uma reflexão crítica sobre a temática.

\section{REFERÊNCIAS}

ABADE, Natascha S. N. As academias a céu aberto em Belo Horizonte: interfaces entre lazer e saúde. 2016. 147 f. Dissertação (Mestrado) - Escola de Educação Física, Fisioterapia e Terapia Ocupacional, Universidade Federal de Minas Gerais, Belo Horizonte, 2016.

AMARAL, Maria T. M.; GOMES, Christianne L. Metodologia da pesquisa aplicada ao lazer. Brasília: SESI/DN, 2005.

AMARAL, Sílvia C. F. Apontamentos sobre produção em políticas públicas de lazer. In: ISAYAMA, Hélder F.; OLIVEIRA, Marco Aurélio T. (org.). Produção de conhecimento em Estudos do Lazer: paradoxos, limites e possibilidades. Belo Horizonte: UFMG, 2014.

AMORIN, Pedro A. R.; LEMOS, Kátia, L. M.; COUTO, Ana Claudia P. In: COUTO, Ana Cláudia P.; SILVA, Luciano P. da; ROQUE, Camila E.; ALVES, Glaude T. (org.). Políticas Públicas de Esporte e Lazer: Centro MG da Rede CEDES. Belo Horizonte: Utopika Editorial, 2019.

ARRETCHE, Marta. Federalismo e políticas sociais no Brasil: problemas de coordenação e autonomia. São Paulo em perspectiva, v. 18, n. 2, p. 17-26, 2004.

BARDIN, Laurence. Análise de conteúdo. São Paulo: Edições 70, 2012.

BELO HORIZONTE, Prefeitura Municipal de. Secretaria Municipal de Esportes e Lazer. Academias a Céu Aberto. Belo Horizonte, 2020. Disponível em: https://prefeitura.pbh.gov.br/esportes-e-lazer/academia-ceu-aberto. Acesso em: 22 nov. 2020.

BELO HORIZONTE (MG). Plano estratégico BH 2030: versão 2016. Belo Horizonte: [s. n.], 2016. Disponível em: https://bhmetaseresultados.pbh.gov.br/content/planejamentoest\%c3\%A9gico-2030.

Acesso em: 22 nov. 2020.

BICHIR, Renata. M. Mecanismos federais de coordenação de políticas sociais e capacidades institucionais locais: o caso do Programa Bolsa Família. Tese. (Estudos 
Sociais e Políticos) Instituto de Estudos Sociais e Políticos, Universidade do Estado do Rio de Janeiro, Rio de Janeiro, 2011.

BRAMANTE, Antônio C. PINA, Luiz W. Formação em programas sociais: PELC e Vida Saudável. Educação à Distância - EaD. Ministério do Esporte. Universidade Federal de Minas Gerais. 2016.

BRASIL. Constituição (1988). Constituição da República Federativa do Brasil, 1988. Brasília: Senado Federal, 1988.

Estatuto da Cidade. 3. ed. Brasília: Senado Federal, Subsecretaria de Edições Técnicas, 2008.2 Disponível em: https://www2.senado.leg.br/bdsf/bitstream/handle/id/70317/000070317.pdf. Acesso em: 11 nov. 2020.

CARVALHO, Melo de A. Cultura física e desenvolvimento. Lisboa: Compendium, 1977.

CHAUÍ, Marilena. Convite à Filosofia. São Paulo: Ed. Ática, 2000.

ELMORE, Richard. F. Disenõ retrospectivo: la investigación de la implementación y las decisiones políticas. In: VAN METER, D. S.; VAN HORN, C. E.; REIN, M.; RABINOVITZ, F. F. \& ELMORE, R. (dir.). La implementación de las políticas. México: Miguel Angel Porrua, 1996.

FREY, Klaus. Políticas públicas: um debate conceitual e reflexões referentes à prática da análise de políticas públicas no Brasil. Planejamento e Políticas Públicas, Brasília, n. 21, p.211-259, jun. 2000.

LASSWELL, Harold D. The Decision Process. Seven Categories of Functional Analysis, College Park, MD, University of Maryland Press, 1956.

LIMA, Luciana L.; D'ASCENZI, Luciano. Implementação de políticas públicas: perspectivas analíticas. Rev. Sociologia Política, Curitiba, v. 21, n. 48, p. 101-110, 2013.

LINHALES, Meily A. et al. Esporte e lazer na Grande-BH, por onde caminham as gestões públicas? In: ISAYAMA, Hélder F.; LINHALES, Meily A. (org.). Avaliação de políticas e políticas de avaliação: questões para o esporte e o lazer. Belo Horizonte: Ed. UFMG, 2008.

LOTTA, Gabriela. (org.). Teoria e análises sobre implantação de políticas públicas no Brasil. Brasília: Enap, 2019.

MARCELLINO, Nelson C. Lazer e educação. Campinas: Papirus, 1987.

Estudos do Lazer: uma introdução. Campinas: Autores Associados, 1996.

MARSHALL, Thomas H. Cidadania, classe social e status. Rio de Janeiro: Zahar, [1950] 1967. 
MELO, Victor de A.; PERES, Fábio de F. Espaço, lazer e política: desigualdades na distribuição de equipamentos culturais na cidade do Rio de Janeiro. Destinos da Cidade: comunicação, arte e cultura. Rio de Janeiro: Eduerj, 2003.

MENICUCCI, Telma. Políticas de esporte e lazer: O estado da arte e um objeto em construção. In: ISAYAMA, Hélder F.; LINHALES, Meily A. (org.). Avaliação de políticas e políticas de avaliação: questões para o esporte e o lazer. Belo Horizonte: Ed. UFMG, p. 179-202, 2008.

Políticas públicas de lazer: questões analíticas e desafios políticos. In: ISAYAMA, Hélder Ferreira; LINHALES, Meily Assbú (org.). Sobre lazer e política: maneiras de ver, maneiras de fazer. Belo Horizonte: Ed. UFMG, p. 136-163, 2006.

MENY, Ives; THOENIG, Jean-Claude. Las políticas públicas. Barcelona: Ariel, 1992.

MINAS GERAIS. Constituição. Constituição do Estado de Minas Gerais [atualizada e acompanhada dos textos das Emendas à Constituição números 1 a 95.] Belo Horizonte: Assembleia Legislativa do Estado de Minas Gerais. 1989. Disponível em: https://bd.tjmg.jus.br/jspui/bitstream/tjmg/706/8/CONSTITUICAO.MG-11.07.17.pdf Acesso em: 22 nov. 2020.

MULLER, Pierre; SUREL, Yves. O que é política pública? Trad. Alceu Ravanello Ferraro. Pelotas: Universidade Católica, 2000.

A análise das políticas públicas. Pelotas: Educat, 2002.

MUNHOZ, Virna C. C. O lazer como direito social na Prefeitura de Belo Horizonte. In: ISAYAMA, Hélder F.; LINHALES, Meily A. (org.). Avaliação de políticas e políticas de avaliação: questões para o esporte e o lazer. Belo Horizonte: Ed. UFMG, 2008. p.59-99.

O'BRIEN, Kevin. J.; LI, Lianjiang. Selective Policy Implementation in Rural China. Comparative Politics, New York, v. 31, n. 2, p. 167-186, Jan,1999.

OLIVEIRA, Débora da S. Políticas públicas de esporte e lazer para pessoas com deficiência no município de Belo Horizonte - MG: desafios múltiplos para a garantia dos direitos. 2020. 105 f. Dissertação (Mestrado) - Escola de Educação Física, Fisioterapia e Terapia Ocupacional, Universidade Federal de Minas Gerais, Belo Horizonte, 2020.

ORGANIZAÇÃO MUNDIAL DE SAUDE. Reducing risks, promoting healthy life. Geneva, WHO, 2002.

PINTO, Leila M. S. de M. Apresentação. In: RODRIGUES, Marilita. A. A.; ISAYAMA, Hélder. F. Um olhar sobre a trajetória das políticas públicas de esporte em Minas Gerais: 1927 a 2006. Belo Horizonte: UFMG, 2013.

POLLITT, Christopher. New Perspectives on Public Services. Place and technology. Oxford: Oxford University Press, 2013.

ROTH, André-Noel. Políticas públicas: formulación, implementación y evaluación. Bogotá: Aurora, 2002. 
RUA, Maria das G.. Análise de políticas públicas: conceitos básicos. Programa de Apoio à Gerência Social do Brasil. BID, 1997.

SANTOS, Flávia da C.; AMARAL, Sílvia C. F. Sobre Lazer e Políticas Sociais: Questões Teórico conceituais. Pensar a Prática, Goiânia, v. 13, n. 3, p. 113, set./dez. 2010.

SILVA, Emília A. P. Costa. et al. Espaços públicos de lazer na promoção da qualidade de vida: uma revisão integrativa. Licere, Belo Horizonte, v.16, n.2, jun/2013.

SILVA, Luciano P. da; PEREIRA, Brisa. A.; SARTORI, Ludmila. M.; ABADE, Natascha. S. N. Orçamento municipal para políticas de esporte e lazer: o caso de Belo Horizonte/MG. In: COUTO, Ana Cláudia P.; SILVA, Luciano P. da; ROQUE, Camila E.; ALVES, Glauce T. (org.). Políticas Públicas de Esporte e Lazer: Centro MG da Rede Cedes. Belo Horizonte: Utópika Editorial, 2019, v. 1, p. 147-168.

SOUZA, Celina. Políticas públicas: uma revisão da literatura. Sociologias, ano 8, n.16, 2006.

STAREPRAVO, Fernando. A.; SOUZA, Juliano. de; JUNIOR, Wanderley. M. Políticas Públicas de Esporte e Lazer no Brasil: uma proposta teórico-metodológica de análise. Movimento, Porto Alegre, v. 17, n03, p. 233-251, jul/set de 2011.

TINÔCO, Dinah. dos S.; SOUZA, Lincoln. M. de; OLIVEIRA, Alba. B. de. Avaliação de políticas públicas: modelos tradicional e pluralista. Revista de Políticas Públicas, São Luís, v. 15, n. 2, 2011.

WINDHOFF-HÉRITIER, Adrienne. Policy-Analyse: eine Einführung. Frankfurt AM Main/New York: Campus, 1987.

\section{Endereço das Autoras:}

Natascha Stephanie Nunes Abade EEFFTO/UFMG

Av. Pres. Antônio Carlos, 6627 - Pampulha

Belo Horizonte - MG - 31.270-901

Endereço eletrônico: natascha_abade@yahoo.com.br

Brisa de Assis Pereira

EEFFTO/UFMG

Av. Pres. Antônio Carlos, 6627 - Pampulha

Belo Horizonte - MG - 31.270-901

Endereço eletrônico: brisadeassis@ hotmail.com 